\title{
Non-Technology Based Approaches to Facilitating Informal Science Learning in Designed Settings
}

\author{
Erik A. Zavrel \\ Department of Biomedical Engineering, Cornell University, Ithaca, NY, USA \\ Email: eaz29@cornell.edu
}

Received 12 May 2016; accepted 31 July 2016; published 3 August 2016

Copyright (C) 2016 by author and Scientific Research Publishing Inc.

This work is licensed under the Creative Commons Attribution International License (CC BY).

http://creativecommons.org/licenses/by/4.0/

(c) (i) Open Access

\begin{abstract}
Informal learning of science occurs in places other than the classroom. Designated venues for informal science learning, known as designed settings, include such institutions as: aquariums, arboretums, botanical gardens, living historical museums, natural history museums, nature centers, planetariums, theme parks, and zoos (collectively referred to as "museums" in this literature review). Museums have undergone a radical transformation from insular institutions indifferent to the experiences of visitors to socially-minded institutions deeply committed to education. To promote learning, museums employ several major non-technology based approaches, including emphasizing relevance to the lives of the visitors and championing social causes, tailoring exhibits to appeal to multiple sensory modalities, carefully considering architectural design and exhibit arrangement, and holding special events that foster long-term memory formation. Museums have made great strides toward becoming inclusive environments that foster informal science learning; however, it is clear they will have to keep abreast of the latest social trends and pedagogical developments to avoid losing relevance.
\end{abstract}

\section{Keywords}

Science Education, Informal Learning, Designed Settings, Museums

\section{Introduction}

Informal learning of science occurs in places other than the classroom. These venues, collectively known as designed settings, include such institutions as: aquariums, arboretums, botanical gardens, natural history museums, nature centers, planetariums, and zoos. Other less commonly recognized designed settings that incorporate ele- 
ments of science include living historical museums and theme parks (Dierking \& Falk, 1992). Herein, the phrase "museum" will be used interchangeably with the aforementioned examples of designed settings.

Museums have undergone a radical transformation from a passive, curatorial role to an active, educational role. This evolution has made museums acutely aware of the need for ways to facilitate science learning amongst their visitors: "Whether people succeed or fail in acquiring new understanding from a museum visit is not necessarily dependent on their intelligence, but on the communication strategy of the museum" (Kavanagh, 1994: p. 6).

While museums may be seen by some as merely a venue in which to idle away a Sunday afternoon, they have the potential to effect dramatic change: "The power of the museum environment cannot be overestimated, because amidst objects from countries and cultures, past and present, lies the potential for deep learning that informs the mind and the body for a lifetime” (Conaty \& Janes, 2005: p. 77). Museums have the potential to alter people's attitudes, values, and behavior (Silverman, 2010).

Often, when informal learning in designed settings is discussed, the importance of personalizing technologies is emphasized: as visitors have unique levels of existing knowledge and seek varying amounts of additional knowledge on a topic, a one-size-fits-all approach to museum exhibits is destined to be found unfulfilling by many. Digital technology facilitates personalization and customization of the museum visit: "Adaptive technologies enable visitors to get personalized information... related to their particular interest, context and path, without time pressure or the involvement of human guides” (Stock \& Zancanaro, 2007: p. 3). Electronic devices can be used to access supplemental information on an exhibit (Falk, 2007). Radio frequency identification (RFID) readers can scan identifying tags on an exhibit to allow automatic, random access to audio and video files associated with a particular exhibit. Electronic response devices-similar to the Clickers used in college classroomscan be used to vote for what an exhibit should display. These devices can also be used to quiz a visitor who can answer questions posed by the exhibit. The interactive exhibit can then provide in-depth explanations (Witcomb, 2003). These devices can also facilitate feedback, permitting visitors to rate exhibitions.

However, less emphasis is typically placed on facilitating informal learning through non-technology based approaches. While often overlooked, these may have even greater potential to promote informal learning. Designed settings facilitate informal science learning using several major non-technology based approaches, including emphasizing personal relevance and championing social causes, tailoring exhibits to appeal to multiple sensory modalities, judicious arrangement of exhibits and careful consideration of the architecture of the setting itself, and holding special events that promote long-term memory formation.

\section{Background}

To best appreciate the lengths to which contemporary museums go to promote informal science learning amongst their patrons, it is illuminating to contrast them with museums of the past. Museums have undergone a profound transformation from their origins to the present. Indeed, the contemporary museum that welcomingly opens its doors to the public and is often the scene of the frenetic activity of children bears little resemblance to the exclusive and stately museum of yesteryear.

In their original incarnation, museums existed as collections of curiosities (Silverman, 2010). They were established amidst the Age of Exploration and served as repositories of artifacts and specimens plundered by the European powers from their far-flung colonies (Mintz \& Thomas, 1998). These collections were menageries, highlighting unique items from exotic lands (Conaty \& Janes, 2005). The old museum paradigm emphasized exclusivity. Museums were established by aristocrats or the elite for their social peers with public access being either sporadic or non-existent (Mintz \& Thomas, 1998). In these museums, the prevailing atmosphere was funereal, with the museum having the feel of a necropolis (Chatterjee, 2008). Access was at the invitation of the proprietor and visitors were careful to exhibit proper decorum, speaking in hushed tones as they marveled at the objects on display (Dierking \& Falk, 1992).

With time, these private collections passed to the state or were entrusted to foundations established by wealthy philanthropists. At a time of increasing industrialization, urbanization, and centralization, governments and business magnates began to adopt responsibility for the public welfare and felt morally obligated to intellectually uplift the citizenry (Hein, 1998). Previously private collections were opened to the public. However, curators felt their role did not extend beyond maintaining and expanding their collections (Weil, 2002).

Only at the dawn of the 20th century was an alternative interpretation of the museum proposed. John Cotton 
Dana, founder and first director of the Newark Museum, proposed the concept of the "new museum", which represented a radical departure from the existing paradigm. He conceived of a museum as a service institution, with the mission of enriching visitors' lives and not the self-serving accumulation of expensive works (Peniston, 1999). It was his ardent belief that museums should be committed to improving the lives of their visitors and not on enhancing their prestige: "All public institutions, and museums are no exceptions, should give returns on their cost, and those returns should be in good degree positive, definite, visible, measurable” (Sandell, 2002: p. 26). Dana's views were picked up and championed by Theodore Low. Amidst the backdrop of the Great Depression, he insisted that museums justify their existence with tangible results (Orosz, 1990).

Faced with dwindling attendance and reduced financial support, museums eventually abandoned their introverted ways and embraced the new paradigm: "During the last quarter of the twentieth century, museums attempted to save themselves from becoming dusty, forgotten, culturally isolated institutions by focusing on audiences and experiences rather than collections and knowledge” (Arnold, 2006: p. 6). In this way, the museum was transformed from an introverted, indifferent institution to an extroverted, considerate one.

\section{Emphasizing Personal Relevance and Championing Social Causes}

Contemporary designed settings promote informal science learning by striving to become relevant to the lives of their patrons. That is, they tailor themselves to their communities (Sandell, 2002). Museums can communicate their relevance through a variety of techniques such as emphasizing personal connection and championing pertinent social causes.

Often, museums develop conservation themes that underscore how the existence and well-being of plants, animals, and people are inextricably intertwined: "With increasing frequency, dedicated exhibits, programs, and new institutions are informing people about pressing issues such as conservation, sustainability, and hunger, fostering individual action" (Silverman, 2010: p. 63). These are most powerful and evocative at living museums (aquariums, arboretums, zoos) (Bell \& Lewenstein, 2009). In these designed settings, visitors encounter the very organisms they are implored to help save. While a poster or flyer may motivate some to mend their harmful ways or provide the impetus for positive action, encountering an aromatic flower at a botanical garden or petting a friendly dolphin at an aquarium will be much more compelling. Cute animals and fragrant plants will naturally evoke a compassionate response from visitors. For instance, Monterey Bay Aquarium recently featured an exhibit on the importance of marine protection that included a petition visitors could sign in an effort to enact legislation protecting marine ecosystems (Silverman, 2010).

The Shedd Aquarium of Chicago promotes a number of local conservation initiatives through its Great Lakes Program. A major component of the program is highlighting the critical role of the Great Lakes in the local economy. For instance, to personalize the issue of invasive species, the program stresses the destructive effects of the introduction of non-native species on the fishing industry in the Great Lakes region (Shedd Aquarium, 2012a). Rather than focus on more abstract reasons for maintaining balance in an ecosystem, the program publicizes how 5th generation fishermen are seeing their way of life disappear due to the depletion of native species.

The Shedd Aquarium also does much to promote awareness about the dangers of overfishing and the very real threat of depleting the oceans of certain fish. As part of the Shedd's sustainable seafood program, Right Bite, local culinary students take field trips to the aquarium to learn about commercial fishing, interact with the impacted animals, and leave with the knowledge necessary to make enlightened, more sustainable seafood choices as they begin their professional careers. The Shedd's website features a downloadable seafood info card, a reference guide designed to be printed out and carried in one's wallet or purse and consulted at the market or restaurant (Bugg 2013). On the card appear lists of fish that are at risk as well as fish that are deemed environmentally-friendly choices. The Shedd also routinely hosts sustainable seafood dinners in which visitors are treated to an educational talk while dining on environmentally sound sushi.

Living historical museums strive to preserve the heritage of the local region. Old World Wisconsin provides a vignette of what 19th century life in rural Wisconsin was like for European immigrants. Different farmsteads reflect the Scandinavian, Germanic, and Slavic culture of the immigrant pioneers who settled the plains ("http://oldworldwisconsin.wisconsinhistory.org," 2013). Genesee Country Historical Village provides visitors a glimpse of 19th century life in rural New York ("https://www.gcv.org," 2013). These designed settings host demonstrations, workshops, and special events that incorporate elements of science that were part of daily life for 19th century farmers and homesteaders such as agriculture, blacksmithing, canning, churning butter, cream 
separation, maple sugaring, soap making, and wool processing (Genesee Country Village \& Museum Educator’s Guide, 2008).

Museums often hold special exhibitions addressing social issues confronting their communities: "Today the world's museums are embracing starkly bolder roles as... vehicles for social change” (Silverman, 2010: p. 2). For example, in response to the distressingly high rates of teen pregnancy and STD infection in the surrounding area, Nottingham Castle Museum and Art Gallery featured an exhibition entitled Sexwise, which centered on issues of teen pregnancy, contraception, and STDs (Dierking \& Falk, 1992).

Museums also host exhibitions related to controversial topics. Visitors to the Body Worlds exhibit, in which plasticized human cadavers are on display, reported resolving to take better care of their physical health after viewing the effects of poor diet, a sedentary lifestyle, and obesity (Silverman, 2010).

\section{Appeal to Multiple Sensory Modalities}

Science learning in designed settings is enhanced when exhibits appeal to multiple sensory modalities: "Information that is gained through multisensory stimulation may provide stronger and longer-lasting memories for that information than for information acquired solely by visual or auditory stimulation” (Chatterjee, 2008: p. 179). To promote long-term retention of memories, it is imperative to stimulate senses other than just sight (Pitman, 1999). To be successful, exhibits must appeal to people of different ages, interests, and preferred learning styles (Lord, 2007). This implies that information must be communicated in different ways.

While some visitors may prefer visually presented information, the illiterate or visually impaired may prefer audio recordings. Even for the sighted, information placards hold limited appeal. It has been found, for example, that visitors read only a small portion of the text in any exhibit and that the more text an exhibit contains, the less they will read (Mintz \& Thomas, 1998).

Learning through touch is becoming increasingly common. Exhibits that provide a tactile experience appeal especially to children. However, haptic learning is also of importance to the elderly (Chatterjee, 2008). Unlike other senses, the sense of touch is not diminished with age. In addition, the sense of touch can be particularly emotive. Children are often shocked when they first touch a snake at a petting zoo. They are astounded to find snake skin dry and scaly, not wet and slimy. Entomology exhibits are particularly powerful haptic experiences. By feeling the myriad small delicate hairs on the body of a tarantula, visitors can intuitively grasp how they function to sense air currents and vibrations. Butterfly pavilions can communicate the dramatic changes that occur during metamorphosis. A visitor can stroke the fuzz on a caterpillar's body and then feel a butterfly alight on his hand. A visitor placing her hands atop the discharge terminal of a Van de Graff generator will come away with a visceral understanding of electrostatic repulsion after having her hair stand on end (Falk, 2007).

\section{Exhibit Arrangement and Architectural Design}

The physical arrangement of exhibits and the architectural features of designed settings can have a profound effect on learning: "Any aspect of the physical context of a museum experience might engage visitors, including the surroundings, the gift shop, and the museum building itself" (Silverman, 2010: p. 16).

There is a strong correlation between the ease with which a complex environment is navigated by the visitor and how much the visitor learns: "Museum space is emphatically three-dimensional, punctuated by three-dimensional objects” (Lord, 2007: p. 6). A hallmark of museums is that they are freely navigated: "People can move around a museum at will and tend to set their own agendas” (Kavanagh, 1994: p. 6). Museums are tending away from guided tours and "directed discovery" in favor of more free-form and unregulated exploration (Lord, 2007). Visitors often explore museums in a non-sequential manner, choosing not to visit exhibits in the order curators intended (Dierking \& Falk, 1992). Crowding of many people in front of an introductory exhibit may cause another visitor to miss it, rendering the rest of the visit less cogent or meaningful if a sequential layout was chosen (Falk, 2007). This is particularly true for smaller visitors as well as patrons with vision or mobility impairments. To ensure confusion does not ensue, designers should take care to minimize interdependence among exhibits, i.e., it is preferable that they stand alone. On the other hand, the architectural layout of a museum can be altered to control the circulation or flow of people. Bottlenecks may intentionally be created to force visitors to file by a key exhibit one at a time.

Lighting is also a crucial design consideration. Lighting can be used in dramatic ways. For example, in the Ancient Egypt exhibits at Philadelphia’s Penn Museum and Chicago’s Field Museum, subdued lighting is used 
to simulate the gloomy tunnels and passageways of a pyramid's interior. Additionally, the lights are recessed into the walls and floors to simulate torches. Learning involves retention; consequently, a visitor is more likely to remember a museum visit if she vividly recalls carefully descending a narrow, winding, staircase with roughly hewn steps to a burial chamber replica where a sarcophagus is on display than a tomb in a glass case in the center of a large well-lit linoleum-tiled room.

Informal science learning can be fostered by not restricting it to the exhibits and infusing it into all aspects of a visit to the museum (Tallon \& Walker, 2008). For instance, many families dine at the restaurant or cafe of a museum. Museums can surreptitiously make a meal into a learning experience by printing facts or trivia on food containers or tray liners (Dierking \& Falk, 1992).

An atmosphere more conducive to learning can be created through the incorporation and expansion of physical amenities such as lounges, restaurants, and cafes. These have several effects, including increasing the time visitors will spend at the museum, making the visit more comfortable and enjoyable so visitors are more likely to return, and fostering social interaction amongst visitors (Lord, 2007). Museums should provide ample areas in which to rest. Rest areas are especially important for the aged and infirm. Benches create an ambiance that promotes loitering and lingering among visitors, who may contemplate, ponder, or discuss an exhibit they just viewed (Dierking \& Falk, 1992).

The setting of the museum itself is critical. A museum dedicated to machines of the industrial revolution may be established in a renovated factory. Objects are often grouped together in rooms to create dioramas or vignettes, providing an overarching theme or context to the exhibit, such as Yesterday's Main Street at Chicago's Museum of Science and Industry.

Museums should appear as welcoming and inviting as possible (Hooper-Greenhill, 1999). The exterior should not intimidate would-be visitors: "Rather than a ponderous museum facade with heavy-weight bronze doors that advertise that going to the museum is a difficult enterprise, fraught with challenges for the uninitiated, the museum approach and entry can be structured to say 'Come on in! There are wonderful things to see and do-this is your museum'” (Lord \& Lord, 2001: p. 70). Prominent signage, such as banners, pennants, or posters, along thoroughfares and walkways can direct confused drivers and pedestrians to the site of a special event.

\section{Hosting Special Events}

Designed settings frequently offer behind-the-scenes tours in which visitors are permitted to explore the exhibits from the point of view of a curator or staff member: "The glamorous side of the exhibitions is what the public sees-the meticulously designed and laid out exhibition galleries, analogous to what happens on stage in the theater. However, just as in the theater no drama can unfold without the backstage crew, so in the museum very little can happen in the galleries without a tremendous effort 'behind the scenes'” (Lord \& Lord, 2001: p. 90). These candid tours are especially popular at living museums like zoos and aquariums. Patrons are often stunned to learn that, at any given moment, the overwhelming majority of items in a natural history museum's collection are not on display (National Museum Directors’ Conference, 2003).

In addition, it has become increasingly common for designed settings to host after-hour events and lock-in parties in which participants spend the entire night. Some events target young children. The Field Museum holds "Dozin' with the Dinos" several times a month. In this program, children spend the entire night at the museum, engaging in workshop activities and flashlight-guided tours of the museum before crawling into their sleeping bags beneath Sue, the most complete and well-preserved Tyrannosaurus Rex fossil ever unearthed (Field Museum, 2013). The Shedd Aquarium hosts “Asleep with the Fishes”, in which young children spend the night engaging in "special programs, games, and hands-on activities" before rising in the morning to see how their "aquatic friends start the day" (Shedd Aquarium, 2012b). Other events target young adults by serving alcohol and touting the event as a unique venue for a first date. The Adler Planetarium in Chicago hosts a monthly "Adler after Dark" event, in which guests can "enjoy cocktails and entertainment against the award-winning view of the Chicago skyline (Adler Planetarium, 2016).

By convincing visitors that they are getting a privileged view, they will experience the thrill of doing something seemingly illicit. Whether that is getting a behind-the-scenes peak at the exhibits or a glimpse of items that have been in storage for decades, camping beneath a towering T. rex, or sipping champagne while strolling the museum grounds, such activities constitute formally-sanctioned rule breaking. At any other time, engaging in such titillating activities would lead to immediate ejection from the premises or even arrest. Such an emotional- 
ly-charged state has been found to be conducive to the formation of long-term memories (Heuer \& Reisberg, 1990).

\section{Conclusion}

Museums have evolved from insular institutions indifferent to the experiences of visitors to socially-minded institutions deeply committed to science education. To promote informal science learning, designed settings employ a host of non-technology based strategies, including emphasizing relevance to the lives of their visitors and championing social causes, designing exhibits to appeal to multiple senses, carefully considering the architecture of the museum and the physical layout of exhibits, and hosting special after-hour events. Museums have made great strides toward becoming inclusive environments that foster informal science learning; however, it is clear that museums will have to keep abreast of the latest social and pedagogical developments to avoid losing relevance. Indeed, museums must avail themselves of all opportunities to continually enhance science learning amongst visitors.

\section{References}

Adler Planetarium (2016). Adler after Dark. http://www.adlerplanetarium.org/adler-after-dark

Arnold, K. (2006). Cabinets for the Curious: Looking Back at Early English Museums. Burlington, VT: Ashgate Publishing.

Bell, P., \& Lewenstein, B. (2009). Learning Science in Informal Environments: People, Places, and Pursuits. Washington DC: National Academies Press.

Bugg, S. (2013). Make 2013 Ocean Friendly... and Delicious. http://www.sheddaquarium.org/blog/2013/01/Make-2013-Ocean-Friendly-and-Delicious/

Chatterjee, H. (2008). Touch in Museums: Policy and Practice in Object Handling. New York, NY: Berg.

Conaty, G., \& Janes, R. (2005). Looking Reality in the Eye: Museums and Social Responsibility. Saskatoon, CAN: University of Calgary Press.

Dierking, L., \& Falk, J. (1992). The Museum Experience. Washington DC: Howells House.

Falk, J. (2007). In Principle, in Practice: Museums as Learning Institutions. New York, NY: AltaMira Press.

Field Museum. (2013). Dozin’ with the Dinos Overnight Packet. http://fieldmuseum.org/sites/default/files/Overnight\%20Packet\%202013_1.pdf

Genesee Country Village \& Museum. (2008). Genesee Country Village \& Museum Educator’s Guide. https://www.gcv.org/Portals/0/pdf/educatorsGuide10.pdf

Hein, G. (1998). Learning in the Museum. London, UK: Routledge.

Heuer, F., \& Reisberg, D. (1990). Vivid Memories of Emotional Events: The Accuracy of Remembered Minutiae. Memory \& Cognition, 18, 496-506. http://dx.doi.org/10.3758/BF03198482

Hooper-Greenhill, E. (1999). The Educational Role of the Museum. London, UK: Routledge.

Kavanagh, G. (1994). Museum Provision and Professionalism. London, UK: Routledge.

Lord, B. (2007). The Manual of Museum Learning. New York: AltaMira Press.

Lord, B., \& Lord, G. (2001). The Manual of Museum Exhibitions. New York: AltaMira Press.

Mintz, A., \& Thomas, S. (1998). The Virtual and the Real: Media in the Museum. Washington DC: American Association of Museums.

National Museum Directors' Conference (2003). Too Much Stuff? http://www.nationalmuseums.org.uk/media/documents/publications/too_much_stuff.pdf

Orosz, J. (1990). Curators and Culture: The Museum Movement in America, 1740-1870. Tuscaloosa, AL: The University of Alabama Press.

Peniston, W. (1999). The New Museum: Selected Writings by John Cotton Dana. Washington DC: The American Association of Museums.

Pitman, B. (1999). Presence of Mind: Museums and the Spirit of Learning. Washington DC: American Association of Museums.

Sandell, R. (2002). Museums, Society, Inequality. London: Routledge.

Shedd Aquarium (2012a). Great Lakes Program at Shedd Aquarium. http://www.sheddaquarium.org/Conservation--Research/Great-Lakes-Chicago/ 
Shedd Aquarium (2012b). Asleep With the Fishes.

http://www.sheddaquarium.org/Documents/Learning-Documents/Overnights/EDU1212_Asleep_With_Fishes_FINAL(2). pdf

Silverman, L. (2010). The Social Work of Museums. London: Routledge.

Stock, O., \& Zancanaro, M. (2007). PEACH—Intelligent Interfaces for Museum Visits. Heidelberg: Springer. http://dx.doi.org/10.1007/3-540-68755-6

Tallon, L., \& Walker, K. (2008). Digital Technologies and the Museum Experience: Handheld Guides and Other Media. New York: AltaMira Press.

Weil, S. (2002). Making Museums Matter. Washington DC: Smithsonian Institution Press.

Witcomb, A. (2003). Re-Imagining the Museum: Beyond the Mausoleum. London: Routledge. http://dx.doi.org/10.4324/9780203361023

\section{Submit or recommend next manuscript to SCIRP and we will provide best service for you:}

Accepting pre-submission inquiries through Email, Facebook, LinkedIn, Twitter, etc.

A wide selection of journals (inclusive of 9 subjects, more than 200 journals)

Providing 24-hour high-quality service

User-friendly online submission system

Fair and swift peer-review system

Efficient typesetting and proofreading procedure

Display of the result of downloads and visits, as well as the number of cited articles

Maximum dissemination of your research work

Submit your manuscript at: http://papersubmission.scirp.org/ 